ACTA UIVERSITATIS CIBINIENSIS - TECHNICAL SERIES

Vol. LXIV No $1 \quad 2014$

\title{
LIGHT-EMITTING DEVICES BASED ON NEW PHENANTHROLINE DERIVATES
}

\author{
MARIUS PRELIPCEANU \\ Faculty of Electrical Engineering and Computer Science Ştefan cel Mare University of Suceava, Romania \\ mprelipceanu@eed.usv.ro \\ ADRIAN GRAUR \\ Faculty of Electrical Engineering and Computer Science Ştefan cel Mare University o fSuceava, Romania \\ adriang@eed.usv.ro
}

\begin{abstract}
An investigation of film forming properties, electrical characteristics, optical and electroluminescence properties of a recently synthesized pyrrolo[1,2-a][1,10]phenanthroline derivatives (RA) has been reported. The results indicate that these new materials can be used for manufacturing organic devices as lightemitting diodes. Various device structure and thickness have been considered in experiments. The poly(pphenylenevinylene)-PPV has been used as transporting layer while the RA as emitting layer. Good rectification behaviour with a switch-on voltage in range of $3 \mathrm{~V}$ and $7 \mathrm{~V}$ has been exhibited by these devices. Yellow-green light with of $96 \mathrm{~cd} \cdot \mathrm{m}^{-2}$ luminance has been found for the OLED based on the double layer structure $100 \mathrm{~nm}$ Indium Tin Oxide(ITO) $/ 50 \mathrm{~nm}$ PPV/60 $\mathrm{nm}$ RA/100 $\mathrm{nm} \mathrm{Al}$.
\end{abstract}

Keywords: OLED, thin film devices, electroluminescence, semiconductor devices.

\section{Introduction}

The efficient organic electroluminescence generated by light-emitting diodes (OLEDs) made by thin films of organic semiconductors and polymers has been the focus of extensive research during the last decades (Parker, 1994, Schrader, 1998, Friend, 1999). Recently, OLEDs have evolved from the stage of scientific curiosity to the numerous optoelectronic devices with significant success on the market. In several important chemical and physical properties of electroluminescent (EL) materials, as well as their synthesis, have been analysed(Parker, 1994, Schrader, 1998). By varying the chemical structure of electroluminescent (EL) materials, the processing and electroluminescent properties can be adapted to specific technical requirements. By studying the electronic transport in RA compounds, a p-type semiconducting behaviour was revealed (Prelipceanu, 2007). In this study, we use the poly( $p$-phenylenevinylene) (PPV) as holetransport layer (HTL) in all OLED structures that have been examined. The pyrrolo[1,2a] $[1,10]$ phenanthrolinederivatives are used as electron transport layer (ETL), after being spin-coated onto PPV.

\section{Experimental}

The molecular structures of materials used in this study are presented in Figure1. Descriptions of the PPV synthesis can be found in the literature (Schrader, 1998, Prelipceanu, 2007). Figures1aandlbshowthe PPVs and some of their derivatives, which are typical HTL materials (Schrader, 1998). In its fully conjugated form, the PPV is insoluble and via a precursor route it can be prepared(Schrader, 1998, Prelipceanu, 2007). The solubilizing side-chains are carried by the substituted PPVs and in common solvents (Prelipceanu, 2007). 
Figure 1.Chemical representation of poly(paraphenylenevinylene)- (a), substituted poly(paraphenylenevinylene) - (b), phenanthroline derivatives -(c).

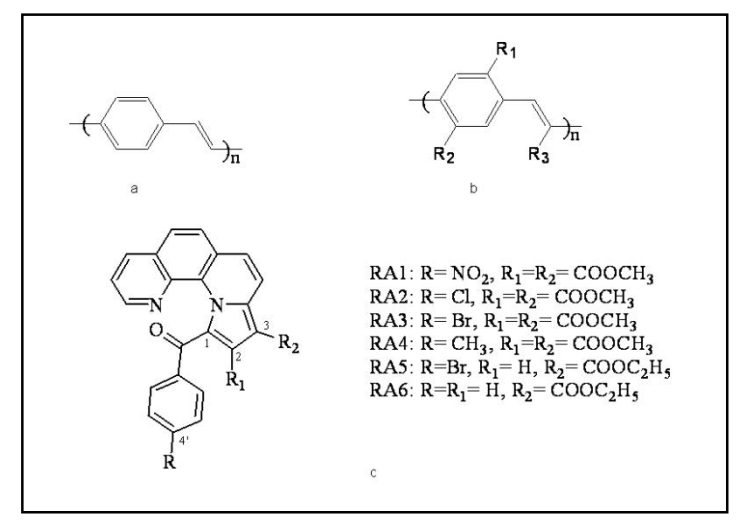

The holetransporting role of the PPV is increase by the electron groups. The alkoxy-side-chains are part of the electron groups.It has been reported that the light-emitting efficiency of PPV-based devices (Pösch, 1998, Parrleitner, 1998, Prelipceanu, 2007)is enhanced by a soluble cyano-substituted PPV (cyanoPPV) (Figure 1b, with $\mathrm{R}_{1}=\mathrm{R}_{2}=\mathrm{n}$-hexyloxy, $\mathrm{R}_{3}=\mathrm{CN}$ ). Usually, the tetrahydrothiophene and $\mathrm{HCl}$ represent the precursor leaving groups, with standard poly ( $p$-phenylenevinylene) precursor. The $\mathrm{HCl}$ can react with the ITO used as substrate, and the result of this reaction will be the forming of the InCl. This can combine into the PPV layer and oxidiseor into the dope the transport materials. We have utilized a PPV precursorto overcome this issue(Prelipceanu, 2007, Leontie, 2005). By using a novel synthetic method on polymerisation, the leaving group is no longer $\mathrm{HCl}$. We baked the substrates at high temperature $\left(280^{\circ} \mathrm{C}\right)$ in vacuum $\left(10^{-6}\right.$ Torr) for two and a half hours after spin-coating the PPV precursor onto ITO-coated glass. We did that to transform the PPV precursor soluble into the insoluble and stable PPV (Schrader 1998, Leontie, 2008,Prelipceanu, 2007).Figure 1cpresents the chemical structure of phenanthroline compounds.Descriptions of the phenanthroline derivatives synthesis can be found in the literature (Leontie, 2005). By spin-coating the solutions of the phenanthroline derivatives of various concentrationswe obtained the thin films. The spin-coating was made at various speeds, in order to optimise not only the film thickness, but the film uniformity and homogeneity on the substrate as well.

Figure 2. AFM investigation for phenanthrolinecompounds on to PPV converted

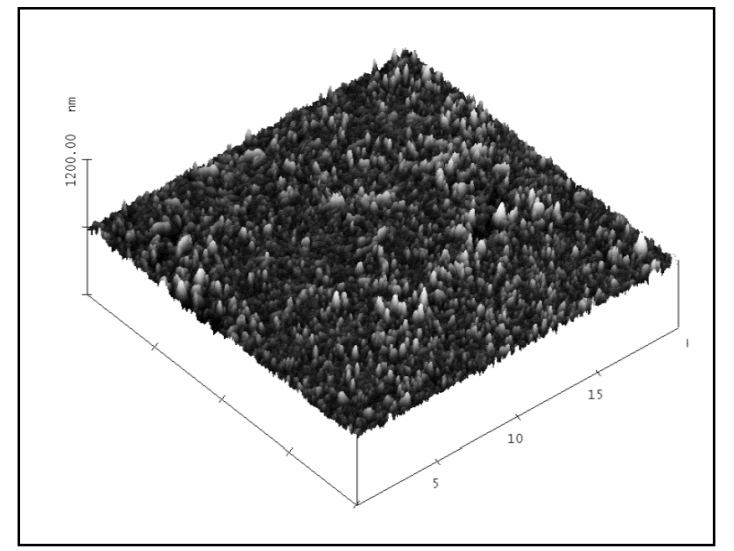

The organic materials were spin-coated onto an ITO-coated glass substrate $(100 \mathrm{~nm})$, as substrates and Al were used as metal electrode. By using a Dektak surface profiler, we measured the film thickness and through the AFM measurements, it was confirmed. Also, by a spectrometer and a luminescence spectrometer, we obtained the films UV-VIS spectra for absorption and photoluminescence for both materials. Then, at a chamber pressure of $1 \times 10^{-6} \mathrm{Torr}$, we vacuum-deposited the aluminium electrode onto the organic layer. Through this process, we fabricated the single layerETLmade by phenanthroline derivatives on top of PPV single layer HTL. Figure 3 represent the OLED structure $\left(2 \times 2 \mathrm{~mm}^{2}\right)$. 
Figure 3. OLED structure side view

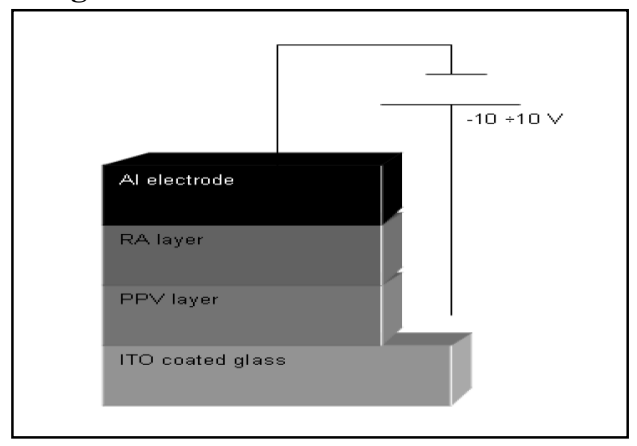

Measuring the luminance emission and current-voltage (I-V), we have been measuring the luminance-current-voltage characteristics. We have prepared six individual OLED samples on one substrate at the same time. Using the positive electrode on ITO we made the efficient organic electroluminescence (EL) measurements, and through the transparent ITO, the emission has been registered.By thermo gravimetric analysis (TGA) the PPV precursor decomposition temperature was determined. We obtained these results by temperature treatment of the PPV with a constant temperature about $10^{\circ} \mathrm{C} / \mathrm{min}$. At $87^{\circ} \mathrm{C}$, the material starts first weight loss due to solvent evaporation. The results showaround $9.17 \%$ weight losses.Because of the thermic degradation of PPV, at $174^{\circ} \mathrm{C}$, the weight loss occurs. According to a standard process, we have previously cleaned the quartz ITO substrates; furthermore, we have dried them in $\mathrm{N}_{2}$ [Schrader 1998]. The deposition of PPV was made byspin coated process at high speed (2000 rpm), from a solution of $50 \mathrm{mg} / \mathrm{ml}$ in analytical grade toluene and chloroform (1:1 v/v) (Prelipceanu, 2007).The spin time was about 50 second. By ellipsometry, we have determined the layers thickness and refractive index $(n)$ of the PPV films at $632.8 \mathrm{~nm}$ wavelength (with an Automatic PlasmosEllipsometer). In Table 1are presented the different values of thickness that were measured and the refractive index for PPV after and before conversion.

Table 1. Thickness and refractive index measurementsfor PPV

\begin{tabular}{|c|c|c|c|}
\hline $\begin{array}{c}\text { Compounds } \\
\text { (on quartz) }\end{array}$ & $\begin{array}{c}\text { PPV precursor } \\
\text { before annealing }\end{array}$ & $\begin{array}{c}\text { PPV annealed 2,5 } \\
\text { hours at 280 } \mathbf{~}^{\mathbf{C}, \text { in }} \\
\text { vacuum }\end{array}$ & $\begin{array}{c}\text { PPV } \\
\text { after second annealing in } \\
\text { vacuum (identical time and } \\
\text { temperature) }\end{array}$ \\
\hline Thickness (nm) & 97 & 45 & 44 \\
\hline Refractive index & 1.3 & 2.59 & 2.57 \\
\hline
\end{tabular}

To measure the thickness of the layers through a contact method, we used a Profilometer (Veeco Instruments). It was measured about $97 \mathrm{~nm}$ thickness (before conversion) for the PPV thin film.

We have discovered that the thickness value (after annealing) is decreasing to about $50 \%$, by the loss mass calculation method. We observed also that the refractive index increase to about $49 \%$, comparing with the original layers. This is shown by the experimental results (Table 1).

The energy level alignment is very important parameter for charge injection in device, at the interface between the organic materials and electrodes(Parker, 1994). For optimizing the charge injection, one important direction is to modify the interface by appropriate surface treatment. By different mechanisms, such as chemical reaction and molecule polarization and charge transfer between the metal electrode and the organic materials, its nature can be explained. The gap state induced by interface formation is also an important process in the dipole layer formation. The Fermi level positions at the interface between ETL and metal electrode are also given by the gap states.It is important to understand if the Fermi level aligns all over the system and what conditions make to happen. The thermal equilibrium occurs at the interface and this is showed by a few works using electrical characterizations (Parrleitner, 1998). The earliest polymer based OLED devices consisted simply of a thin film of polymer sandwiched between two metal electrodes of different work functions. The injection conditions for holes and electrons show us the efficient and quality properties of an organic led. The positive and negative charges are usually unbalanced in a single layer structure. The situation differs where the metal electrodes are well matched to the energetic levels of the organic materials used. The principal carrier can traverse the complete structure in the unbalanced situation, without finding an opposite carrier to recombine. In our case we have a lost energy and it leads to a pure efficiency in the transformation of electrical power into optical power. For this 
reason we considered that the multiple organic thin films need to be added for achieving a better balance. One organic layer matching the anode, PPV in our structure, which enhances the transport of holes and one organic thin film, RA in this case, matching the cathode enhances the transport of electrons. The injection of the free carriers can be compensating this way. A barrier at the organic/organic interface occurs. The carriers tend to gather in this region and this improves the carrier's recombination. We obtain in this way the relaxation process to the ground state and light emission (Schrader, 1998, Pösch, 1998).

\section{Results and discussions}

The ultraviolet absorption spectra of thin film structures that were used in experiments, RA compounds/PPV is presented in Figure4.Also is presented the PPV spectra after and before conversion.For the PPV, the layer thickness was about $50 \mathrm{~nm}$. For the RA compounds, the layer thickness was around 50$60 \mathrm{~nm}$. We observe strong absorption at $\lambda_{\max }=440 \mathrm{~nm}$ in the spectra of the films, due to the $\pi \rightarrow \pi^{*}$ transition of the phenyl groups, with a shoulder at about $\lambda_{\max }=480 \mathrm{~nm}$. The positions of the most intense peaks are presented inTable 2 .

The strong band peaked at $\lambda_{\max }=400 \mathrm{~nm}$ characterises the absorption of thin PPV film (Figure4).

\section{Figure 4. UV-VIS absorption spectra of RA derivatives and PPV in thin films}

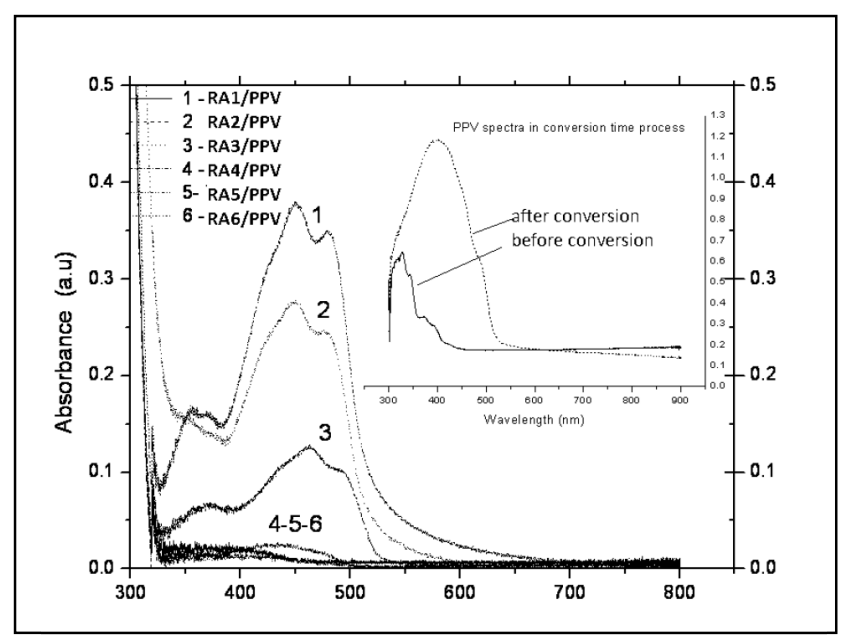

Table 2.UV-Vis absorption measurement for PPV/RA structures.

\begin{tabular}{|c|c|}
\hline Films & $\boldsymbol{\lambda}_{\max }(\mathbf{n m})$ \\
\hline PPV/RA1 & 438 \\
\hline PPV/RA2 & 440 \\
\hline PPV/RA3 & 460 \\
\hline PPV/RA4 & 450 \\
\hline PPV/RA5 & 400 \\
\hline PPV/RA6 & 400 \\
\hline
\end{tabular}

Electrochemistry measurements of RA compounds thin films were made to study the charge transport and the stability. In Figure 5 the cyclic voltammetry results are shown two reversible oxidation peaks corresponding to a good stability for studied material. The experiment was made with the standard ferrocene/ferrocenium redox system. Considering the value of $-4.8 \mathrm{eV}$ as the HOMO level standard for calibration system, we calculated the HOMO level of the material witch is $-5.1 \mathrm{eV}$. The obtained value is fit well with the work function of electrode metal. 
Figure 5.Electrochemistry measurements of RA compound thin films ( $\mathrm{Ag} / \mathrm{AgNO}_{3}$ as reference electrode).

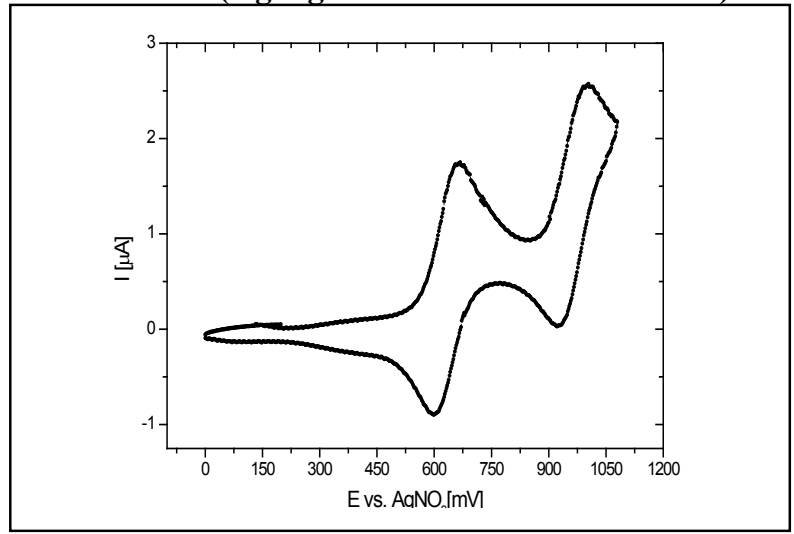

In Figure 6we have shown the electrical characterisation for the device structures (PPV/RA1PPV/RA4). A clear rectification is shown by all examined structures. We observed also that, the aluminium used as cathode electrode can influence the shape of respective curves.

Figure 6.Field dependence of the current density of OLED devices.

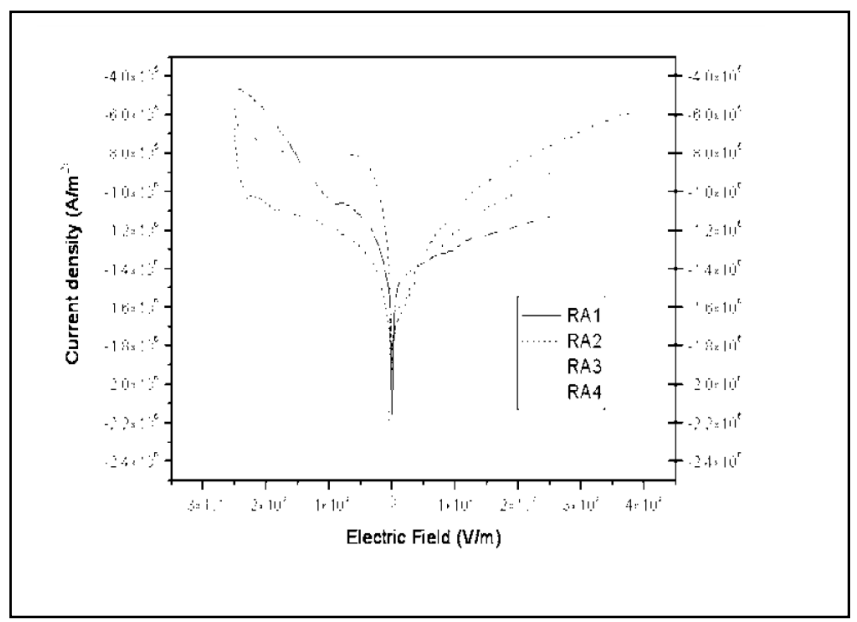

We measured only four first devices because forcompounds RA5 and RA6, it was observed poor absorbance spectra. Figure 7shows the current-voltage characteristics for positive region.

Figure 7. Current-voltage characteristics of RA 1-4 /PPV devices (positive region)

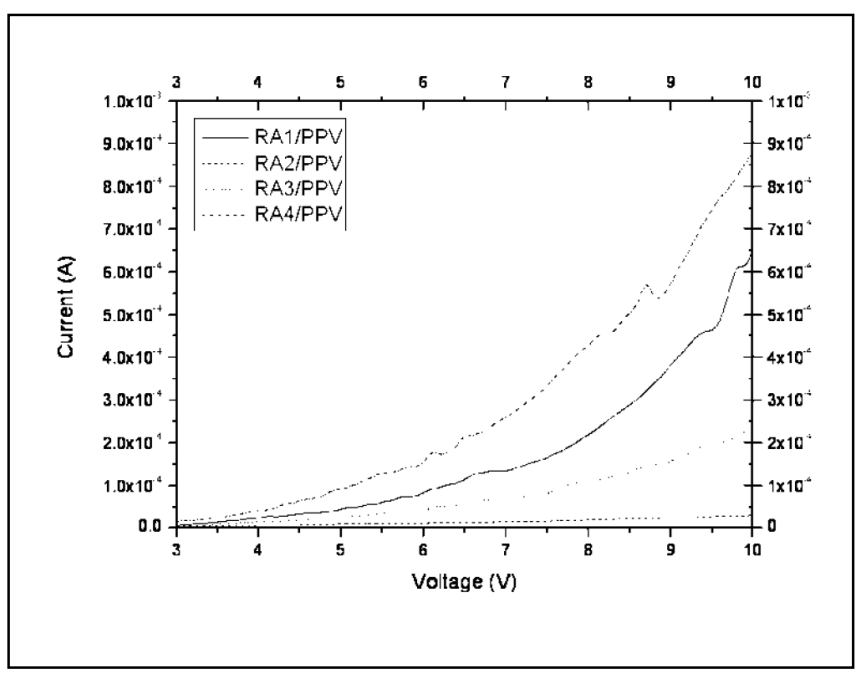

Devices PPV/RA1 and PPV/RA2 have a start-on voltage of about 6 and for this reason we extend the electrical characterisation until to $20 \mathrm{~V}$ applied.This is presented in Figure 8 . The light emission can be measured only from the devices PPV/RA1 and PPV/RA2. 
Devices PPV/RA1 and PPV/RA2 emit in the yellow-green with a luminance of $90 \mathrm{~cd} \cdot \mathrm{m}^{-2}$ and 96 $\mathrm{cd} \cdot \mathrm{m}^{-2}$ as well. The devicesPPV/RA3 and PPV/RA4 emit yellowish-green light emission, but we could not detect their luminance because they were too weak. For our functional devices, we will note the $96 \mathrm{~cd} \cdot \mathrm{m}^{-2}$ luminance as a reference, at a field about of $1.5 \times 10^{6} \mathrm{~V} / \mathrm{cm}$.

Figure 8.Brightness vs. voltage characteristics of OLED device

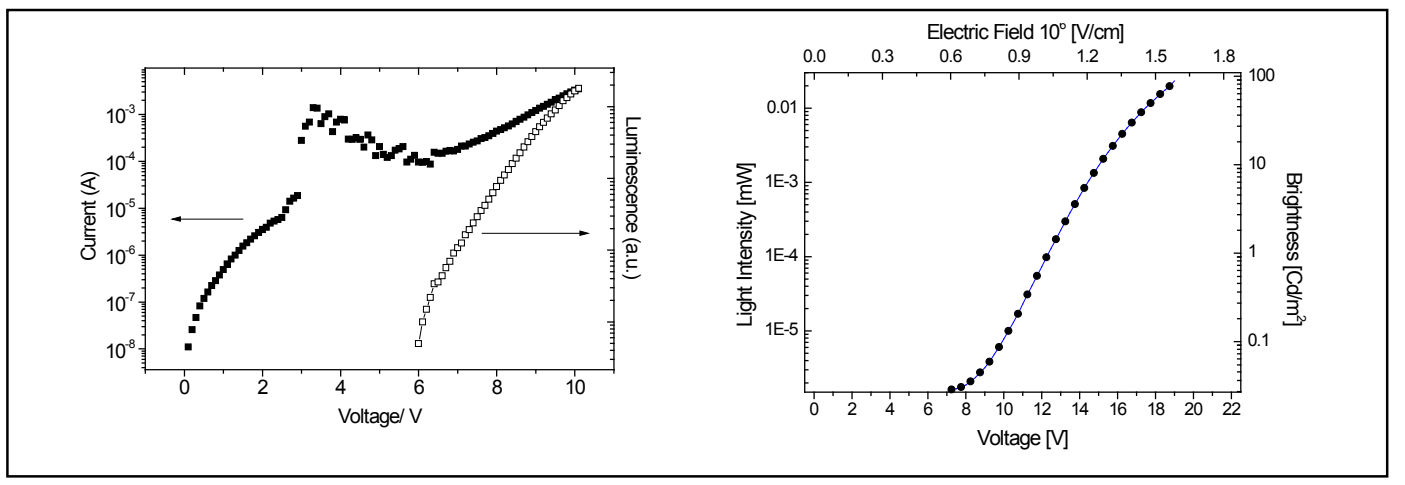

The OLED have light emission at about $6 \mathrm{~V}$ and are not observed change in the slope of the current -voltage curves. That can be explained by the injected holeswhich are not transported through the film. In this case, we assume that the recombination zone is near to the ITO electrode and energy transfer to the electrode combined with quenching of excitons can take place efficiently. We will improve the electron injection at the PPV/RA interface in order toaccumulate the holes. In this way, the turn-on voltage could decrease, and consequently, the power efficiency can be improved.

\section{Conclusions}

We have studied the characteristics of double layer (ITO/PPV/RA/Al) organic light-emitting devices. Clear rectification behaviour is shown by all devices, with a turn-on voltage at6. The most successful OLED emitted in the yellow-green colour with a luminance of $96 \mathrm{~cd} \cdot \mathrm{m}^{-2}$.We consider that a future multilayers device (PPV/RA/PPV/RA) can increase the luminance performance because nonemitting triplet states are generated when two charge carriers combine at multiple interfacesto form an exciton.

\section{Acknowledgment}

This work was supported by "Q-DOC - Improving the quality of doctoral studies inengineering sciencesto support the developmentof the knowledge society - Contract POSDRU/107/1.5/S/78534" and by the Romanian National Program II, Young Research Team no. 107/06.08.2010. We gratefully acknowledge the support of Prof.Dr.Sigurd Schrader, from TFH Wildau, Germany, for allowing the measurements performed in his lab, as well as of Prof.Dr.LiviuLeonte and Dr. R. Danac, from "Al.I.Cuza" University of Iaşi, Romania for providing the phenanthroline derivatives. We are also thankful to Prof.Dr.MihaiDimian for the helpful discussions related to this article.

\section{References}

- Friend R. H., Gymer R. W., Holmes A. B., Burroughes J. H., Marks R. N., Taliani C, Bradley D.D.C., Dos Santos D.A., Bredas J.L., Logdlund M., Salaneck W.R., (1999) "Electroluminescence in conjugated polymers", Nature 397(6715) pp. 121-128.

- Leontie L., Druta I., Danac, R., Rusu G.I., (2008), "Electronic transport properties of 1-(p-Rphenacyl)-4-\{[(1'-ethylcarboxylate)-(3'-p-R'-phenacyl)]-7'-indolizinyl $\}$ pyridinium bromides in thin films", Thin Solid Films 516 (7), pp. 1599-1603.

- Leontie L., Druta I., Danac R., Prelipceanu M., and Rusu G.I., (2005), "Electrical properties of some new high resistivity organic semiconductors in thin films", Progress in Organic Coatings 54 (3)), pp. 175-181.

- Parrleitner R., Tasch S., Leising G., Scherf U., (1998) "Improved electron injection in organic light-emitting devices by applying thin insulating layers", Mater. Res. Soc. Symp. Proc. 488, pp. 69-74.

- Parker I.D., Kim H.H., (1994) "Fabrication of polymer light-emitting diodes using doped silicon electrodes", Appl. Phys. Lett. 64(14) pp. 1774-1776. 
- Pösch P., Fink R., ThelakkatM.,. Schmidt H.W, (1998) “A comparison of hole blocking/electron transport polymers in organic LEDs", ActaPolym. 49 pp. 487-494

- Prelipceanu M., Prelipceanu O.S., Tudose O.G., Leontie L., Grimm B., Schrader S., (2007) "Study of thermal conversion and patterning of a new soluble poly (p-phenylenevinylene) (PPV) precursor", Materials Science in Semiconductor Processing 10, 77-89, 2007. Materials Science in Semiconductor Processing 10, pp. 77-89.

- Prelipceanu M., Tudose, O.G., Prelipceanu O.S., Schrader S., Grytsenko K.,(2007) "Study of oriented growth of oligofluorene-thiophene films onto aligned vacuum-deposited polytetrafluoroethylene layers", Materials Science in Semiconductor Processing 10, pp. 24-35,

- Prelipceanu M., Prelipceanu O.S., Leontie L. and Danac R., (2007), "Photoelectron spectroscopy investigations of pyrrolo[1,2-a] [1,10]phenanthroline derivatives", Physics Letters A 368 (3-4) pp. 331-335.

- Schrader S., Rieß W., Vestweber H., Koch N., (1998), „New Polymeric Heterolayer Systems for Efficient Light-emittig Devices“, SPIE 3476, pp.188-194. 